\title{
Turn taking behavior in dual earner households with children: a focus on escorting routines
}

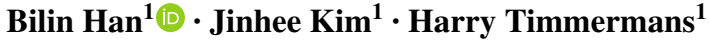

Published online: 28 February 2018

(c) The Author(s) 2018. This article is an open access publication

\begin{abstract}
This article discusses results of a study on turn taking behavior in escorting children in dual-earner households. Using a multinomial logit model, the probability of different turn taking routines in escorting children is analyzed as a function of age and gender of the children, personal and household characteristics of the parents, properties of the job, and day of the week. Two types of turn taking behavior are examined. The first concerns routines in which during a single day one of the parents drops off the child and the other parent picks up the children again after completing the concerned activity (school, day care, outdoor activity). The second concerns routines in which one of the parents takes full responsibility and commits to all escorting duties on a particular day and the other parent does the same on another day of the week. Results, based on a sample of dual-earner households, indicate that turn taking represents a substantial, yet smaller share of escorting activities. The propensity of turn taking behavior is higher for highly educated, highincome dual-earner households. Fathers show the tendency of dropping off the children in the morning. Mothers tend to take responsibility for more flexible escorting needs.
\end{abstract}

Keywords Task allocation · Turn taking behavior · Escorting · Dual-earner households · Gender role

\section{Introduction}

Organizing daily life in dual earner households with children is anything but easy. Parents face the challenge to meet the ever-increasing job performance criteria, nowadays with decreasing job security. They need to generate sufficient income to be able to pay for a house, buy a (second) car and support their children, knowing that the costs of daycare (in the study area: The Netherlands) are virtually equal to minimum income levels. They need

Bilin Han

b.han@tue.nl

1 Department of Urban Science and Systems, Urban Planning Group, Eindhoven University of Technology, Eindhoven, The Netherlands 
to invest time in raising and parenting their children, spend time on running their household and find the time to escort their children to school, day care and various sports and leisure activities. They feel the pressure to spend quality time as a family. And, last but not least, they need to free the time to meet with their social network, both personally and as a family, and get engaged in personal recreational and leisure activities to have a moment for themselves to recuperate from all those activities, tasks and errands when often they do not have much choice as others dictate the timing and rhythm of their daily lives, certainly during weekdays.

An abundant volume of literature in sociology, social psychology, education research, health studies, spatial sciences and travel behavior research has examined different facets of this problem, including subjective well-being, health, financial aspects, children education and their development path to independence. Travel behavior research and urban planning/geography have studied how the spatial distribution of activity locations, jointly with institutional regulations and the multimodal transportation system offer opportunities and at the same time enforce space-time constraints affecting how personal and household activities are manifested in time and space. The decision problem of households is how to realize their needs and desires, considering their job and other commitments, within the space-time action space that defines time-dependent choice options and the travel options they have available, which also discriminate options in time and space (Rasouli and Timmermans 2014a, b, c; Liao et al. 2014).

Institutional constraints strongly limit the time windows to conduct particular activities and influence the start and end times of other discretionary activities. Some jobs involve fixed work schedules as they are organized in work shifts. Even if workers have flex hours, meetings that come with uncertain end times characterize their jobs, adding to the complexity of the household activity scheduling process. Workers may feel pressure, as they cannot afford canceling meeting requests or leaving early too often. At the same time, school start time hours are fixed and even though schools may have facilities and programs for extracurricular school care, parents have to pay for it and still need to pick up their kids at a certain time at the latest. Day care centers have similar arrangements. As a final example, children and/or parents may be engaged in voluntary or leisure activities in the evening that involve particular pre-arranged time slots and therefore influence the available time window to prepare and have dinner, getting ready for such activities and going to the activity location. If multiple individuals are involved with different time slots and different activity locations, travel arrangements may become problematic.

If this is not complicated enough, in cities and regions with highly congested transportation systems, parents also need to cope with the uncertainty that comes with travel times. While there is always a remote chance of accidents, cancellation of public transport services or the car breaking down, it is unlikely that parents take this into consideration when arranging their daily schedule. On the other hand, structural variability in travel times is learned. Parents become aware of it and dependent on their risk attitudes make choices under uncertainty (Schwanen and Ettema 2009; Rasouli and Timmermans 2014d). They may have arranged fallback security protocols for such situations such as a parent or friend picking up the child, but not everyone has family living nearby while friends may be in the same predicament. Because one or both parents may need to travel substantial distance, especially for such dual-earner households, the potential negative aspects of their risky decisions may be substantial. Timmermans et al. (1992) found that dual-earner households tend to reach a balance where the job preferences of the male tend to dominate his job location choice whereas females tend to have more to say about the choice of residential 
location which tend to be closer to her job location. It is one means of limiting the probability of these extreme situations to happen.

The literature on task allocation in (dual earner) households has devoted a lot of attention to task allocation and school travel. Although differences between results of these studies can be observed, they share some regularities. First, there is substantial evidence that parents' travel patterns and children's travel to school are synchronized (e.g., McDonald and Aalborg 2009; Deka 2013; Hsu and Saphores 2014; Colley and Buliung 2017). School start times and departure times of work commutes tend to be correlated (e.g., Fox et al. 2015; Deka 2017; Mehdizadeh et al. 2016); Ehteshamrad et al. 2017a, b) unless fixed work schedules preclude such synchronization. This correlation tends to be weaker when children become older and therefore more independent, and when the built environment, distance to school and general safety in the area are inducive to children traveling independently without any escort (e.g., Fyhri et al. 2011; Giles-Corti et al. 2011; Elias and Katoshevski-Cavari 2014; Mitra and Buliung 2014; Lin and Chang 2010; Pojani and Boussauw 2014; Lopes et al. 2014; Lam and Loo 2014; Kyttä et al. 2015). Meanwhile, the spatial synchronization, such as location of parents' work place and school, also affect parent's escorting activity (e.g., He 2013; He and Giuliano 2017; Ermagun and Levinson 2016). For instance, He (2013) showed that the probability of a child being escorted by parents will increase with decreasing distance from the mother's workplace to school.

Second, although variables such as parental employment status, work hours and flexibility of work hours (e.g., Vovsha and Petersen 2005; Yarlagadda and Srinivasan 2008; Gupta et al. 2014) and the age of the child and parent (e.g., Tetali et al. 2016; Scheiner 2016) significantly affect the propensity of escorting children to school or day care, gender seems the most dominant factor explaining escorting behavior. Ceteris paribus, children tend to be more escorted by their mothers than fathers (e.g. Fyhri and Hjorthol 2009; Barker 2011; Ekert-Jaffé 2011; Scheiner and Holz-Rau 2012, 2017; Hjorthol and Vagane 2014; Bernardo et al. 2015; Motte-Baumvol et al. 2017). This gender difference is not only clearly noticeable in the tendency to escort children and the time spent with children, but also in experienced stress and subjective well-being (e.g., Offer 2014; Feng and Boyle 2014).

Although our knowledge of escorting behavior and task allocation decisions in (dualearner) households has accumulated substantially, a limitation of these empirical studies and the associated mathematical models of group decision making (e.g., Zhang et al. 2002, 2005; Bradley and Vovsha 2005; Gliebe and Koppelman 2005; Srinivasan and Bhat 2006; Ermagun and Levinson 2016; see Ho and Mulley 2015 for a recent overview) is their exclusive focus on single escorting events. Turn taking behavior has not been considered explicitly with one exception (Ettema and Van der Lippe 2009).

Turn taking behavior may manifest itself in multiple ways. One of the parents may drop off the child at school or daycare while the other parent is picking up the child. If not enforced by work schedules, this decision strategy freezes up some flexibility for one of the parents on that specific day. This routine may also be induced by parents' opinions about parenting. An alternative turn taking strategy is to share the responsibility of escorting for different days of the week. In this case, if parents are not forced to enact this strategy, it creates more flexibility for one of the parents for a full day, and may also offer some mental relief in that a parent is released from the responsibility of being on time at school/ day care. Finally, turn taking behavior may be reflected in a pattern that one of the parents takes the responsibility of escorting during weekdays (working days), while the other parent is responsible for escorting during the weekend (non-working days). If the non-working days coincide with the weekend, this pattern will likely involve different activities of the 
child such as escorting the child to training or sports matches or other out-of-home leisure activities.

To enhance our knowledge of turn taking behavior, the current paper reports the results of a series of analyses about the prevalence and covariates of different turn taking strategies in the context of escorting children to school and other activities. The study is empirical in nature and attempt to identify tendencies in turn taking behavior. In particular, it reports the results of an analysis of turn taking behavior on the same day of the week, and the results of an analysis of taking turns for different working days. A multinomial logit model, which predicts the probability of a particular turn taking strategy, relative to other task allocation strategy is estimated. The other strategies differ between the two analyses because their prevalence depends partly on the turn taking strategy. We report estimated coefficients and their significance and for easier interpretation the associated probabilities of choosing a particular strategy.

The remainder of this paper is structured as follows. First, we document the data collection and discuss sample characteristics. Next, we discuss the results of descriptive and statistical analysis of different turn taking strategies. Finally, we complete the paper with a discussion of the implications of the findings for future research.

\section{Data collection and sample characteristics}

The data for this study were collected using a web-based questionnaire. Respondents were recruited from a national panel and thus are located across the whole country. In addition to personal data and responses about job application decisions, the survey contained information about the daily schedules of the parents and their children. The data on the children included information whether or not they were escorted and if so by whom. The survey took 20-50 min to complete.

The data were collected in January 2015 in the Netherlands. This paper is based on the part of the data concerned with socio-demographic characteristics, the work schedules of the adults, and children-related agendas. The total number of households is 1037. After checking the data, 615 dual-earner households with escorting activities during weekday valid questionnaires were used for the present analyses.

The frequency distributions of the selected socio-demographic characteristics are shown in Fig. 1. The percentages for the four household income categories are 3.9, 8.8, 42.6 and 44.7 respectively, indicating that the majority of the households earn more than 2800 Euros/month. The percentage households in which both parents having a low level education is only $1.3 \%$ compared with $29.6 \%$ of both having a middle level education level and $33.2 \%$ both having a high education level. In $18.5 \%$ of the households males have a higher level of education than females, and in $17.4 \%$ of the households females have a higher level of education than males. The frequency distribution of the number of children in a household is $48.3,44.1$ and $7.6 \%$ respectively, indicating that more than 90 percent of the households only has one or two children. Recall that we only included dual earner households with children in our sample. $56.1 \%$ households have a boy as the youngest child, while $43.9 \%$ households have a girl as the youngest child; In $37.2 \%$ of the households, the youngest child is younger than 5 years old, while the percentage of the youngest child being between 5-8 years and 9-12 years old is $28.8 \%$ and $34.0 \%$ respectively.

Figure 2 depicts the distribution of the number of working hours per week and the distribution of working days across weekdays. The percentage males working more than $32 \mathrm{~h}$ 

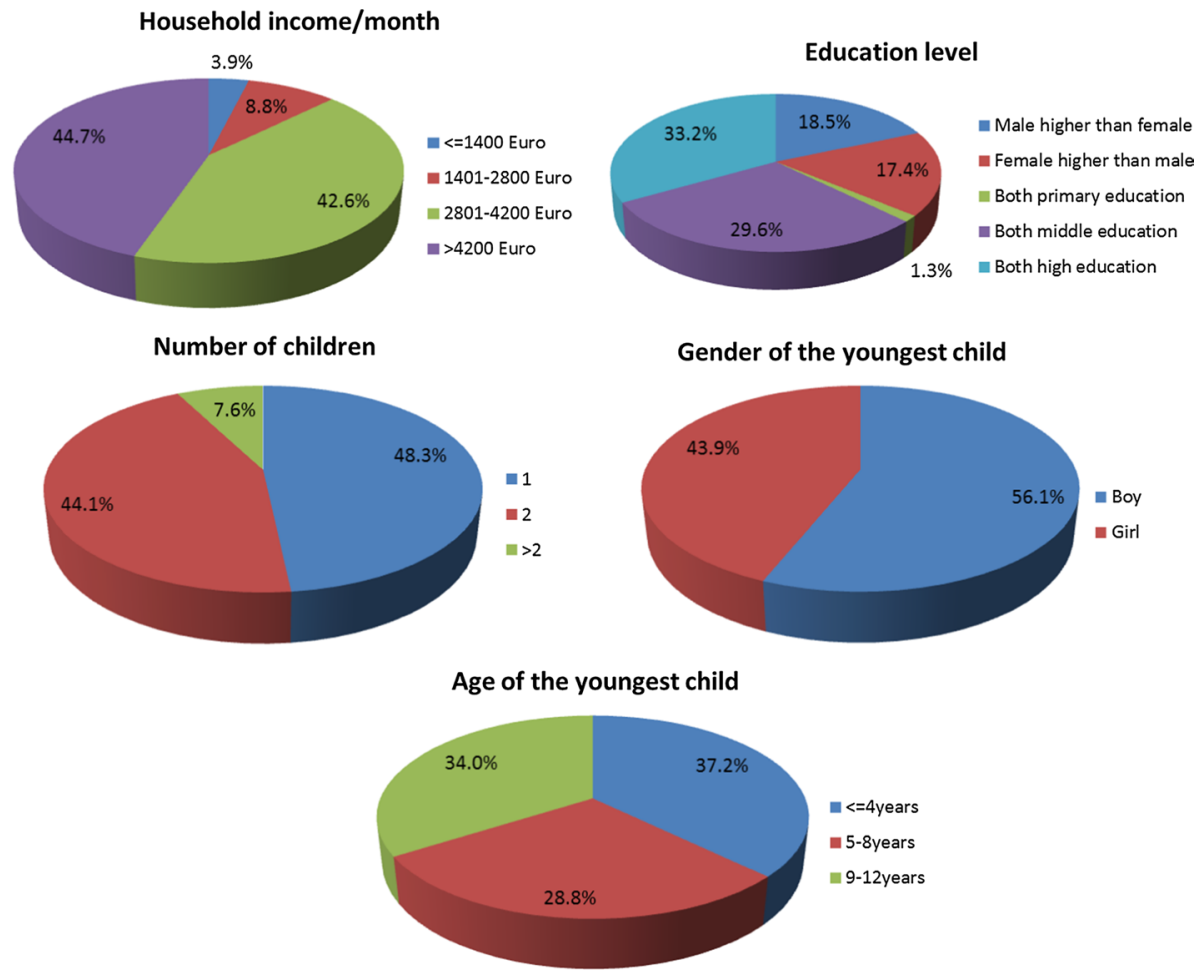

Fig. 1 Sample characteristics $(N=615)$
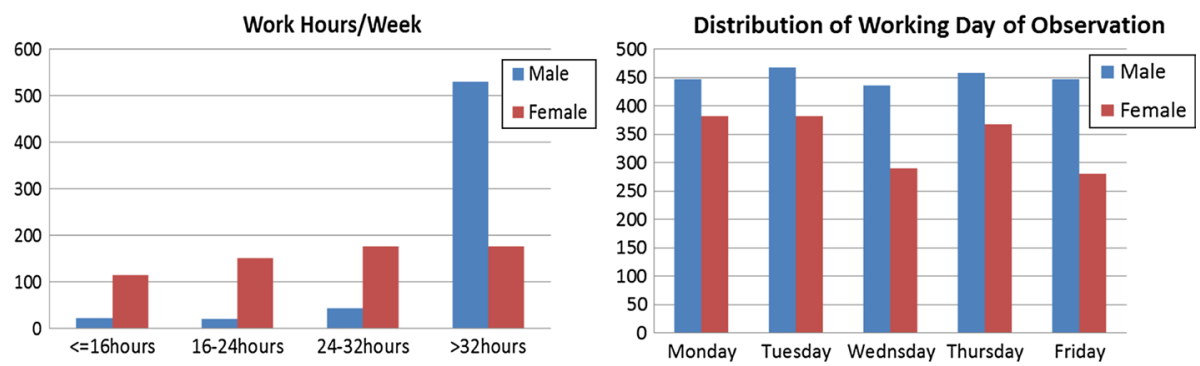

Fig. 2 Work schedules information

per week is 86.4 , which is much higher than the $28.5 \%$ for females, suggesting that males work longer than females on average. This finding is congruent with the Dutch population at large. Women participation in the labor market is among the lowest in Europe. Similarly, as shown in Fig. 2, the percentage males working on a weekday is also higher than the percentage females. Wednesdays and Fridays are the days of the week when less people work, especially females work less on these days. To understand these statistics, it is important 
to realize that elementary schools tend to be closed on Wednesday afternoon. Friday is a popular non-working day for people working part-time.

\section{Analyses and results}

\section{Taking turns on the same day}

We first report the results of an analysis of turn taking during the same day. Such behavior is reflected in one of the parents dropping off a child at the day care, school or activity location and the other parent picking up that child later that day when the activity is completed. Before discussing the results of a multinomial logit model, conducted to analyze the prevalence of such turn taking behavior and its covariates, we report the frequency distribution of the occurrence of different kinds of escorting routines. Table 1 lists the frequencies of the different escorting options. Because either parent may be responsible for dropping off the child, we differentiate between mother-father (MF) and father-mother (FM) turn taking behavior. To assess the relative frequency of this behavior, in addition we identify cases where one of the parents is responsibility for both dropping off and picking up the child ('MM' and 'FF'). In addition, we distinguished the patterns in which one of the parents either drops off or picks up the children, while the child either travels alone or is escorting by someone else for the either leg of the trip ('Half F-half O/None' and 'Half M-half O/ None').

The results show that for our sample of dual-earner households, the option in which the mother both drops off and picks up her children is the highest (34.54\%). This is not a surprise in the sense that an overwhelming number of prior studies have emphasized the gendered organization of childcare (e.g. Fyhri and Hjorthol 2009; Barker 2011; Ekert-Jaffé 2011; Scheiner and Holz-Rau 2012; Hjorthol and Vagane 2014 etc.). Next, across all trips, travelling alone/other options are most prevalent. As we will later, this percentage is relatively high because many older children are not escorted. Although each of the turn-taking strategies for the same day represents a small percentage, together they are responsible for almost one quarter of all trips of the children.

The results of the multinomial logit model are listed in Table 2. Because the estimated coefficients are difficult to interpret in terms of the probability that a particular escorting pattern will be observed, we also calculated the choice probabilities. These are listed in Table 3. The dependent variable is the probability of a particular escorting routine on a single day. The explanatory variables include working hours across parents/week, work status, household income, number of children in the household younger than 12, education level of the parents, the gender and age of the child and days of the week. All explanatory variables were effect-coded.

The explained variance of the logistic regression is substantial as indicated by a Pseudo $\mathrm{R}$-squared value of 0.19 . The estimated constants of the various escorting options again

Table 1 Frequencies of the different escorting options on the same day

\begin{tabular}{|c|c|c|c|c|c|c|c|}
\hline & $\mathrm{FF}$ & MM & FM & $\mathrm{MF}$ & $\begin{array}{l}\text { Half } \mathrm{F} \\
\text { half } \mathrm{O} / \text { none }\end{array}$ & $\begin{array}{l}\text { Half } \mathrm{M} \\
\text { half } \mathrm{O} / \text { none }\end{array}$ & Other/none \\
\hline$\%$ & 10.15 & 34.54 & 8.70 & 6.62 & 3.68 & 7.24 & 29.06 \\
\hline
\end{tabular}




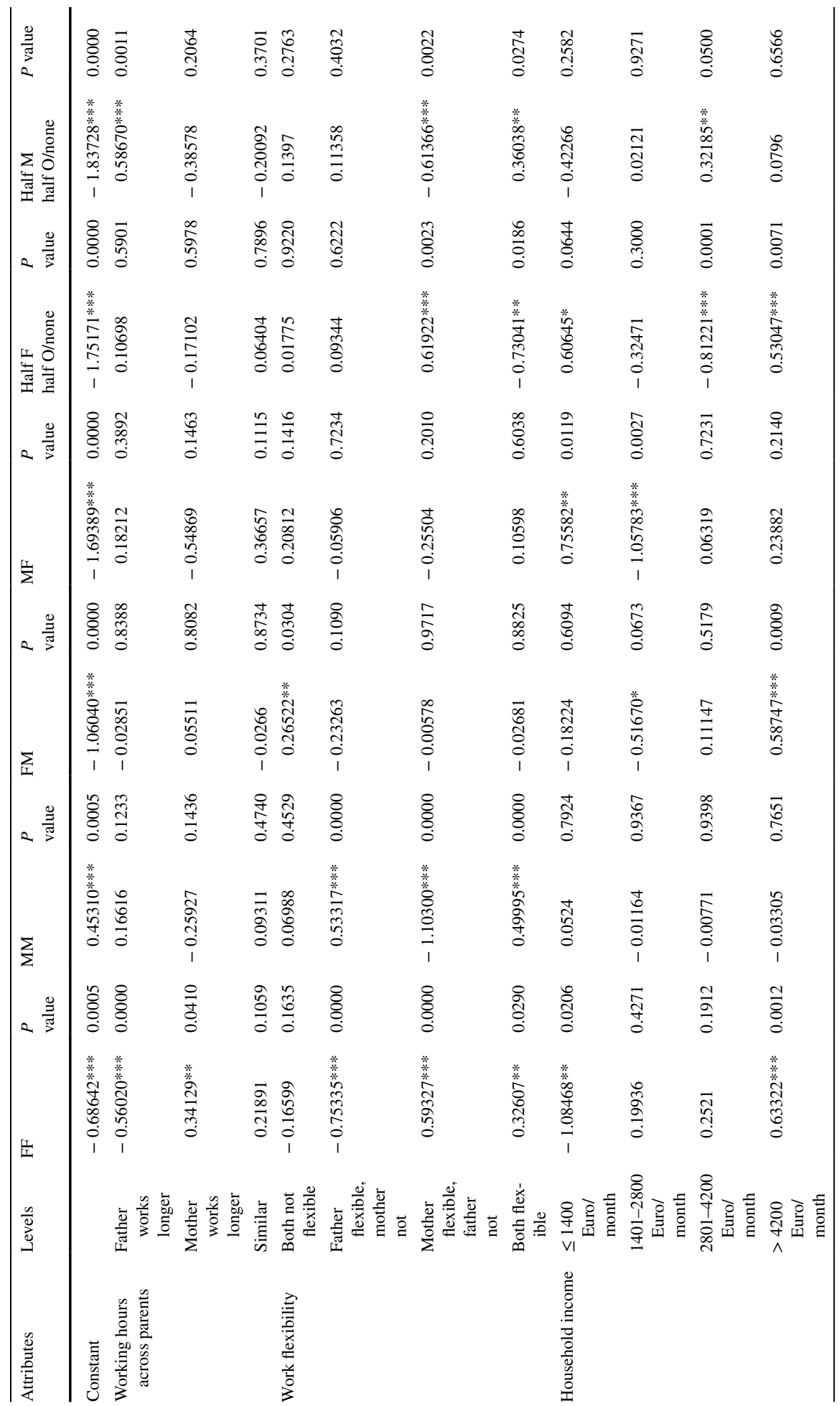




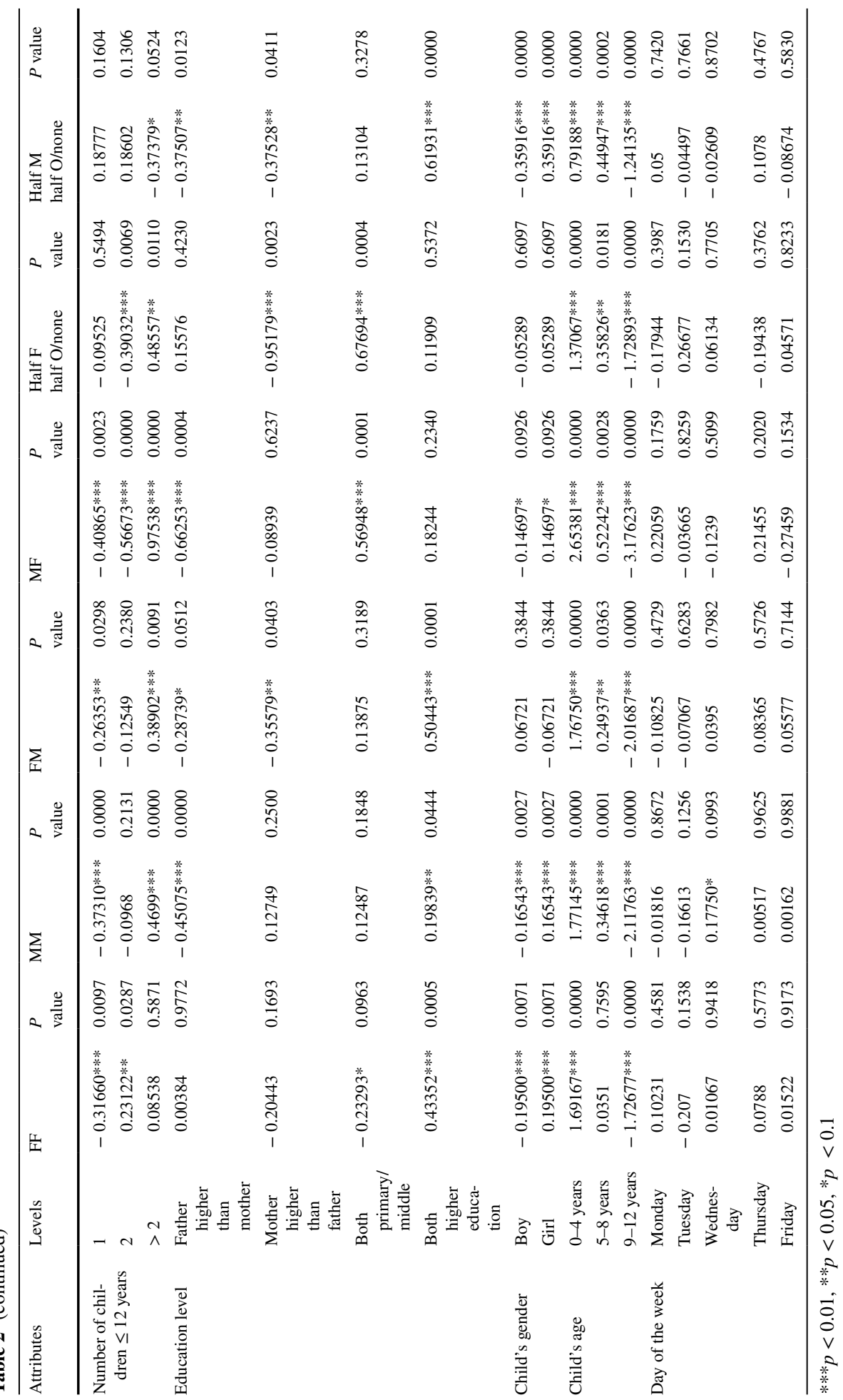


evidence that, ceteris paribus, women dropping off and picking up their children is most prevalent. It represents almost $40 \%$ of all escorting. In around $25 \%$ of the trips of the children, they travel either alone or are accompanied by a person other than one of the parents. Next, fathers only take the next largest share of daily escorting. The constants thus suggest that turn taking behavior is relatively infrequent. The share of the FM patterns is almost double the share of the reverse MF pattern. In turn this is roughly the same as the importance of patterns in which either the drop off or the pick-up part does not involve a parent.

Tables 2 and 3 provide the estimation results for all escorting patterns and all covariates. Because the present study concerns the prevalence and covariates of turn-taking behavior, we limit our discussion to these escorting options. Focusing on the effect of the parents' working hours, none of the estimated effects is significant at the conventional 5\% probability level. The probability of the FM and MF pattern is slightly higher if the parent works longer hours. It suggests that the parent working less hours tends to pick up the child. This seems intuitive in that the parent who works less has more flexibility. Synchronizing schedules and less stress coping with uncertainty then seems to lead to this turn-taking behavior.

As for work schedule flexibility, among the estimates associated with the FM patterns, only the estimate of the case, in which the work schedules of both parents are not flexible is positive and significant. In this case, the probability of turn taking behavior is higher, as is the probability that children travel alone or are escorting by non-parents. In this case, the probability of the FM patterns is almost twice as high as the probability of the MF pattern, suggesting that when both parents' work schedules are not flexible, the father tends to bring the child to the day care, school or activity location and the mother picks up the children. Interestingly, and in line with the dominance of gender in escorting, once the mother has more flexibility than the father, the probabilities of both patterns is reduced, and they appear more equally. Vice versa, however, if the father has more flexibility, it is not equally reflected in more escorting. Under these circumstances, the probability that the child travels alone or is escorted by people other than the parents increases significantly, the probability of the FM and MF patterns if hardly different from the situation that none of the parents have a flexible work schedule. In other words, flexibility in the father's schedules hardly affects the escorting tendency and responsibility of the mother. Inviting others to escort the children solves the fact it is more difficult for the father to escort the children.

Table 2 also shows that three of the four effects for the lower income categories are significant. The probability of engaging in turn taking behavior is higher when either the household income belongs to the lower category or the higher. However, the probabilities of the two different sequences are dramatically different. For households with a lower income, the MF pattern is more prevalent than for households with a higher income. Considering the finding that fathers take a larger share of escorting in higher income households, the result suggests that overall gender differences are somewhat smaller in these households, but at the same time the pattern in which fathers drop off the child and mothers pick them up again is more distinct for this household category.

All effects on the turn taking strategies for one or two children households are negative, and three out of the four are significant. As the number of children younger than 12 years of age increases, the percentage traveling independently or being escorting by someone other than one of the parents drops significantly. In part, this finding reflects a confounding, but watered-down effect of the age of the children. If the household has less than 3 children, the FM patterns clearly dominates the MF pattern and their probabilities of occurrence is virtually the same if the household has one child or has two children. In case of more than 2 children, the extra help of the father is clearly needed. However, subtle and highly interesting shifts can be observed. The share of mothers taking only responsibility 


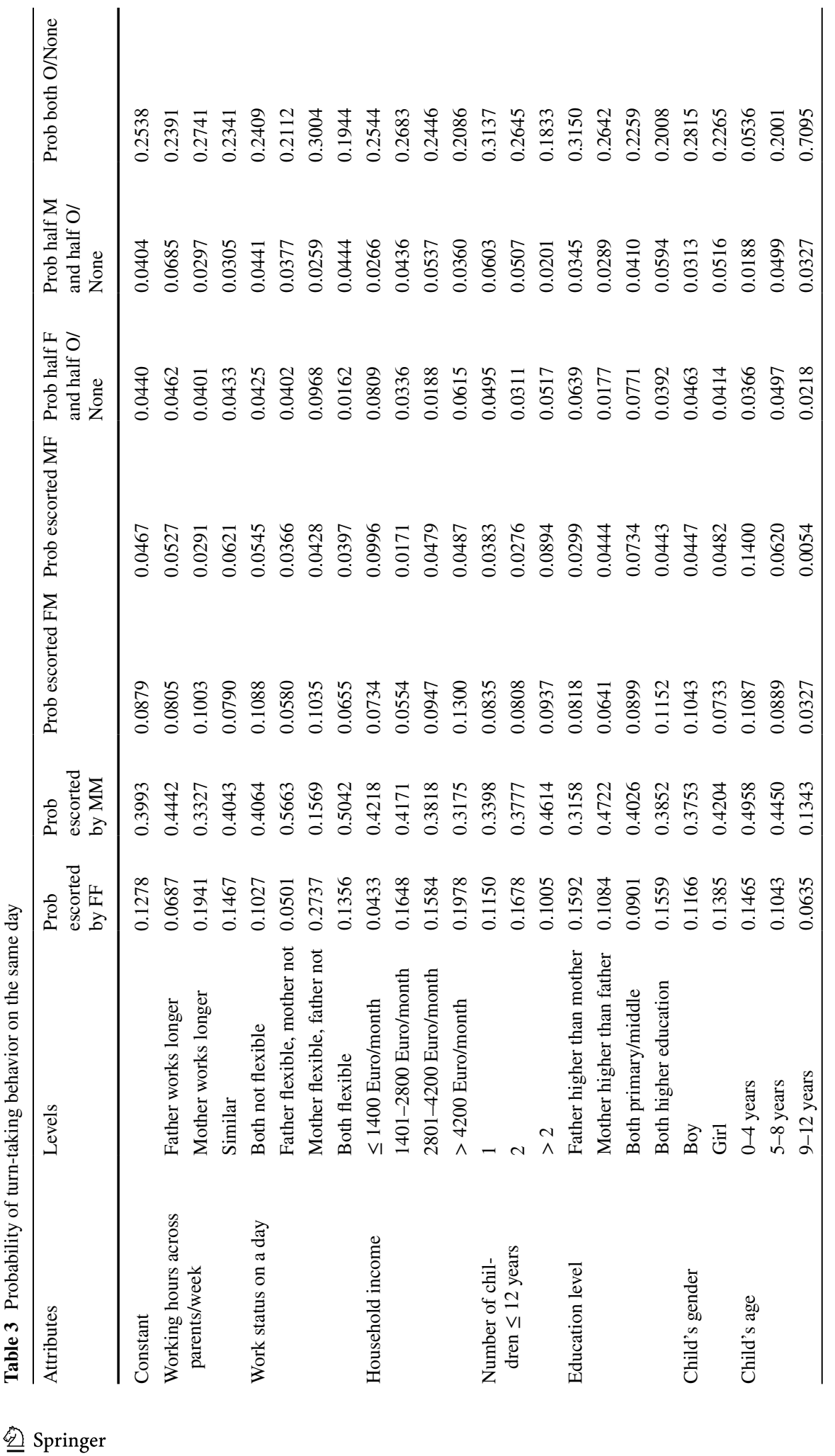




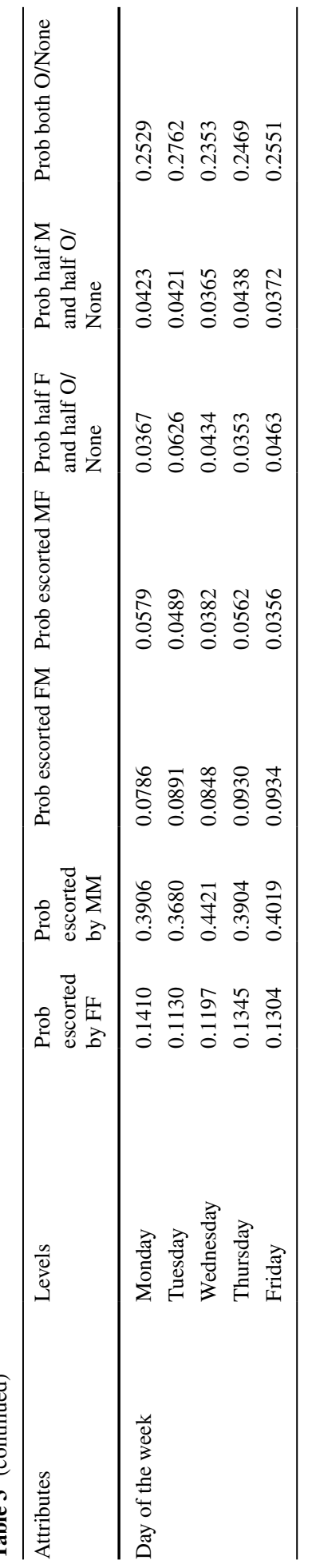


for escorting increases. In addition, independent travel of the children and escorting by non-parents increases. Simultaneously, the role of the father shifts in that the share of trips where the both drop off and pick up the child is reduced, while the share of FM patters increases a little.

The estimated effects of the education levels of the patterns indicate that if both parents have a high education, the FM routine is further accentuated. The probability of observing this escorting routine is strongly affected by the other categories for education. Vice versa, and in line with earlier results, if both parents have lower or middle level education, the probability of the MF routine slightly increases.

The gender of the child does not affect the probability of the MF pattern. However, the reverse FM pattern in which the father drops off the child is more pertinent when the child is a boy. This may point at a gender-match effect, particularly for fathers, who seem to prefer escorting their sons slightly to their daughters.

The estimated effects and calculated probabilities for the child's age are also highly interesting. All effects for the two turn taking strategies are significant for the two lowest age categories. Once the child becomes older than 9, the probability of not being escorted by one of the parents increases to approximately $71 \%$. At this age, the role of the father drops rapidly. In $6 \%$ of the cases, they remain responsible for all daily escorting; the probability of the FM routine is reduced to about 3\%, and the share of the MF pattern is smaller than $1 \%$.

Finally, as for days of the week, differences are very small. None of the estimated effects on the turn taking strategies are significant. The share of the MF patterns is somewhat reduced on Wednesdays and Fridays. This may reflect the fact that schools tend to be closed on Wednesday afternoons, while women, who work more part-time tend not to work on Fridays. Depending on the distribution of working days of observation across weekdays, the percentage of women work on Wednesday is the lowest, followed by Friday.

\section{Taking turns on different days}

Another way of coping with the balancing act of job, household, children and personal time is that one of the parents is released from the responsibility of escorting for a full day and the other parent (or maybe someone else) does all the escorting on that day. On another day, these roles and tasks are reversed. The potential advantage of this strategy is that it reliefs a parent, at least physically, from the effort that comes with escorting. In turn, it means this parent is not as much faced with the work schedule, and temporal and institutional constraints in participating and scheduling discretionary activities and travel. What is more, the parent likely can organize the day into larger blocks of consecutive time to participate in activities, should not worry about being at locations at certain times and the associated uncertainty, and is likely less hampered by fragmentation of time.

To analyze the prevalence of this coping strategy and the effects of covariates, a multinomial logit mode was estimated. The dependent variable consists of a set of decision strategies, the explanatory variables of a set of socio-demographic, child characteristics and job conditions that in part may affect the work schedule. The following coping strategies were distinguished. In addition to parents' turn turning across different days of the week, we differentiated between one of the parents taking full and only responsibility, turn taking between one of the parents and someone else, task allocation within the same day, combination of escorting and independent travel during the same day and independent travel or escorting by someone other than the parents. Because we are interested in work schedule 
and turn taking behavior, we selected from the data only the weekday when at least one of the parents worked.

Results are listed in Tables 4 and 5. The model describes the data well as indicated by the Pseudo R-squared value of 0.14. The estimated constants for the model indicate that both task allocation and turn taking behavior are less chosen options than the other travel options we identified. Turn taking is slightly less popular than task allocation within the same day (8.9 vs. 9.1\%). The probability of turn taking across different days of the week substantially increases if the mother works more hours than the father. It suggests that only once the difficulty of juggling with the many tasks becomes too complicated or too much for mothers to handle, fathers tend to step in. The probabilities indicate that under such circumstances, parents first try to involve another person to escort the child. In contrast, if fathers work longer, this strategy is chosen slightly less.

Household income does not seem to affect the probability of parents adopting turn taking across different days of the week much. Only for the highest household income category, the result shows that parents tend to adopt turn taking bur rather than involving the other parent another person is asked to take care of escorting the child.

The effect of the number of children in the household seems consistent with this tendency. If the number of children exceeds two, the probability of turn-taking and releasing one parent from the obligations of escorting increases. However, the probability of the two parents taking turns is hardly affected. Rather, another person is involved to free the parents from escorting.

Education levels of the parents do not show any significant effect. The probability of turn taking behavior for different education levels also does not exhibit a clear pattern. Similarly, the gender of the youngest child does not seem to significantly influence turntaking behavior on balance, even though Table 4 shows that the effect for boys is significant. There is some evidence that boys are more allowed to travel independently.

Finally, an interesting effect is observed for the age of the child. The probability of parents turn taking behavior across days of the week systematically decreases with increasing age of the child. In contrast, it increases for those types of turn taking that involve another person. Because this category includes independent child travel, these effects thus seem to indicate that independent travel rapidly increases if the child becomes older.

\section{Conclusions and discussion}

Research on mental stress and social well-being in coping with the accumulative pressure of work, running a household, and parenting and escorting children, particularly among women, has been widely reported in the literature. The need for some time for oneself brings some relief, if only temporarily. It is interesting to learn that the bike ride home or reading a book on the train are some precious moments to recuperate from the constant pressure of work and family. Turn taking behavior is another strategy to create some temporary relief, at least physically, either as part of the day or for a full day if turn taking involves one of the parents taking the responsibility of escorting and child care for a full day.

Although there is a vast literature that has reported the results of analyses of escorting behavior, with a sociological, educational, health, economic or spatial perspective, surprisingly the literature on turn taking behavior is very modest indeed. To reduce this void, the aim of this study has been to empirically examine the prevalence of different turn taking routines and the effect of covariates. In particular, we examine turn taking during a single 
day in which one parent drops off the child and the other parent picks up the child, and between-day turn taking in which parents transfer their escorting responsibility or tasks from 1 day to the other.

Results of the analyses suggest that although turn taking behavior can be detected, it plays a much lesser role than task allocation in the sample of dual-earner households used in this study. Taking turns within a day seems a more often used coping strategy than turn taking across different days of the week. The results of the analyses may be interpreted to indicate that turn taking becomes relatively more pertinent when the dominant pattern of women escorting the children is no longer sufficient to cope with the challenges of job performance, running the household, personal time and escorting and parenting the children. This seems primarily caused by both parents working (close to) full time and decreased and differential space-time flexibility reflected in narrow space-time prisms. Under those circumstances fathers tend to help out a little, and then turn taking behavior in which they drop off the children and the mothers picking up the children is the most popular routine.

In closing this paper, we wish to emphasize that common for this type of research, the conclusions depend strongly on our interpretations of the statistical findings. The estimated model fits a particular mathematical expression to the data, resulting in a set of coefficients, which depends on the chosen statistical model. This model summarizes and in some sense generalizes the underlying uni-and multidimensional frequency tables. By definition, therefore, the validation of the interpretation is relatively poor. Our understanding of the context and conditions under which particular turn taking routines tend to become prevalent would benefit by completing this (dominant) research approach with controlled games and experiments in which the researcher can control the context and conditions and household are asked what choice they made in case they would face the manipulated scenario. Turn taking strategies and escorting activities in general are the outcomes of household scheduling behavior. As we indicated, such scheduling decisions also involve other activities and are influenced by possible job work schedule constraints, parents' preferences, gender roles, social influence, values about parenting, relative to other life domains, institutional factors and space-time, and resource constraints. A better understanding of the process requires more detailed and dedicated data about all the influential factors and processes. Moreover, where job schedules are flexible, it may also be true that daily agendas of the spouses are organized and synchronized around escorting. Variability in turn taking then in part would be a matter of a routine, but would also reflect temporal variability in the flexibility or lack of it in the agenda of a parent. Again, such more subtle scheduling processes require dedicated data and more advanced household level scheduling models. Nevertheless, the focused empirical analysis reported in this paper is still of interest to describe the phenomenon of turn-taking behavior and the effects, if any, of covariates.

Keeping these limitations in mind, the results of this study on the turn taking strategy has some important policy implications. With an increasing number of women participating in the work force, traditional gender roles in household task allocation will increasingly be challenged and come under pressure. In addition, with inequality of education fading out, social norms and personal preferences about quality of life and life careers will like further change. Under those circumstances, possible turn taking behavior in dual-earner households may release one parent from temporal-spatial pressures owing to work and other activities. However, current privatization of childcare and strong government regulations has resulted in significant financial consequences for households. As the affordability of childcare depends on household income, inequality and maybe social exclusion results. Particularly for low salary jobs, the hourly net income is less that the hourly costs of daycare, implying that unemployment rates stay unnecessarily high. Rather than 


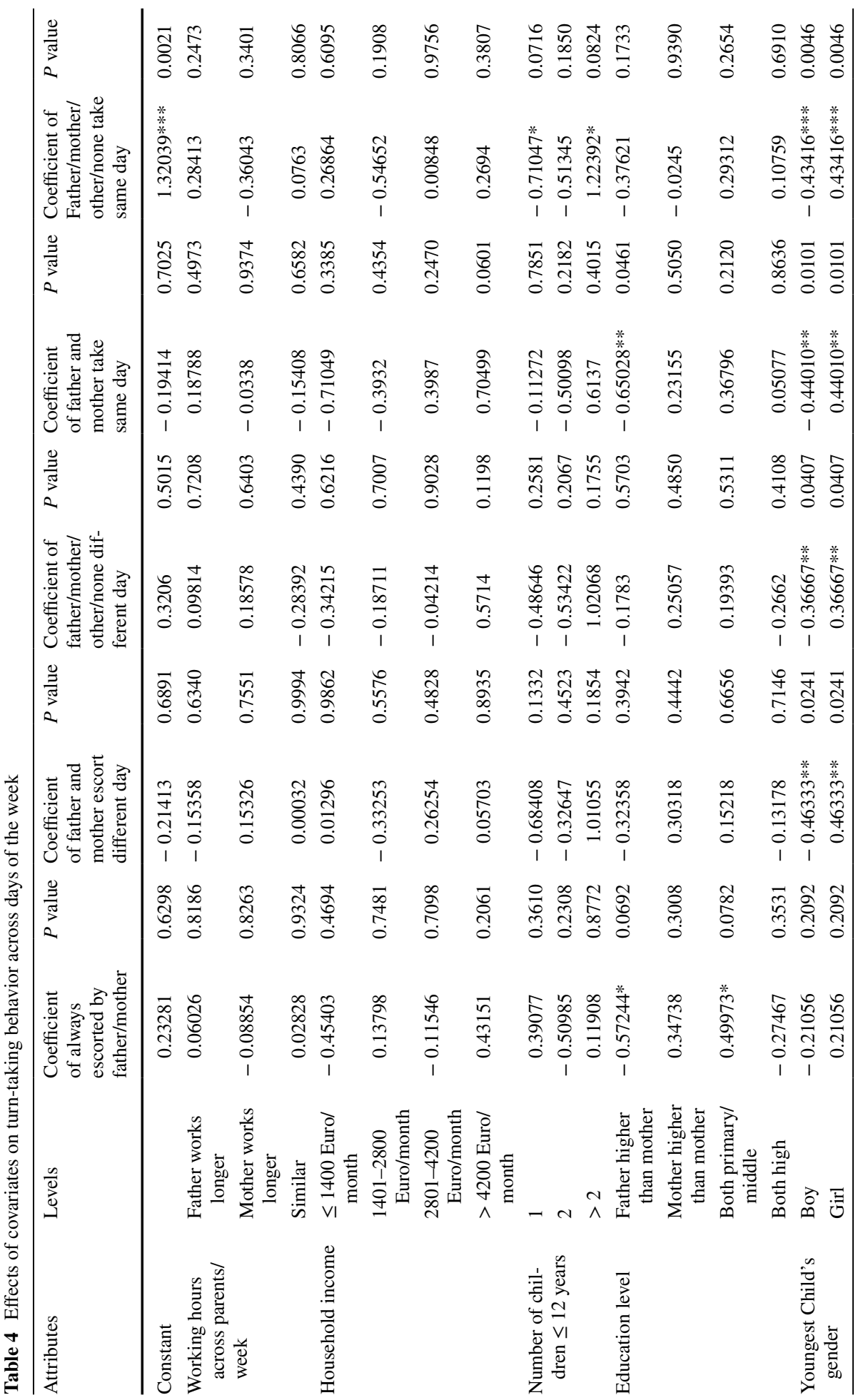




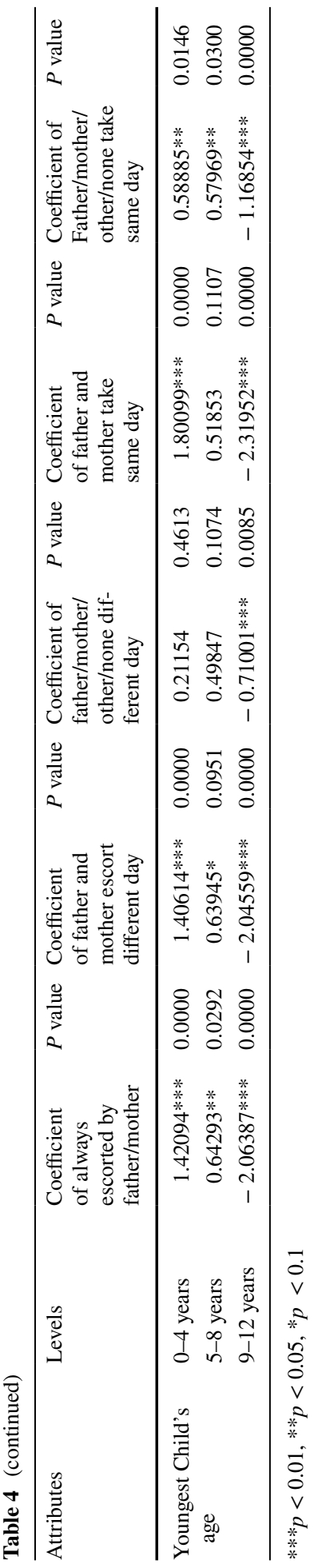




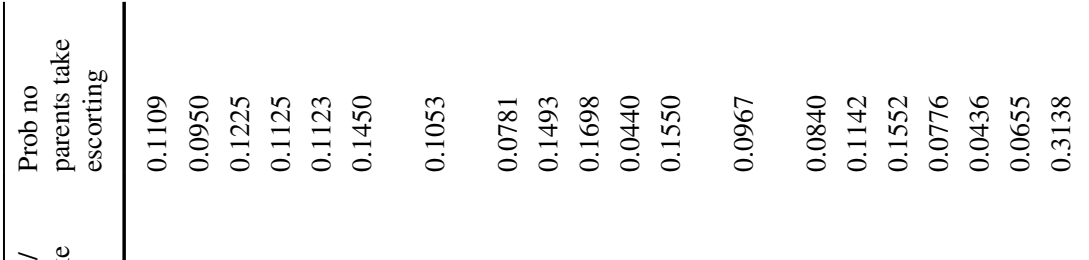

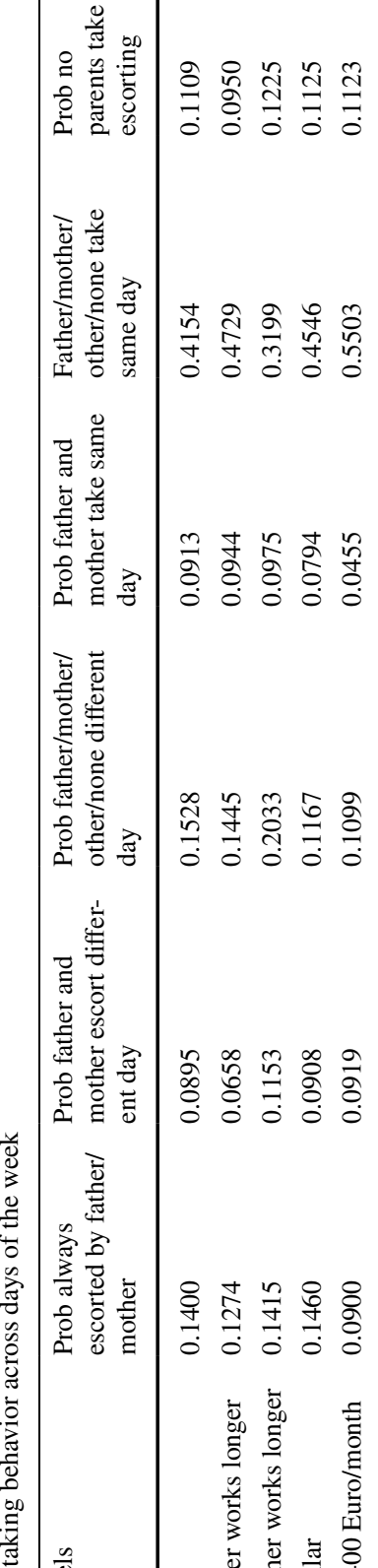

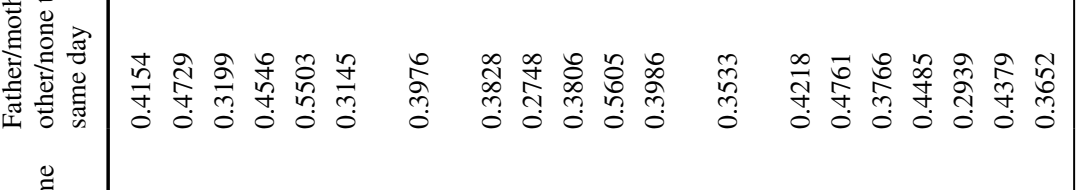

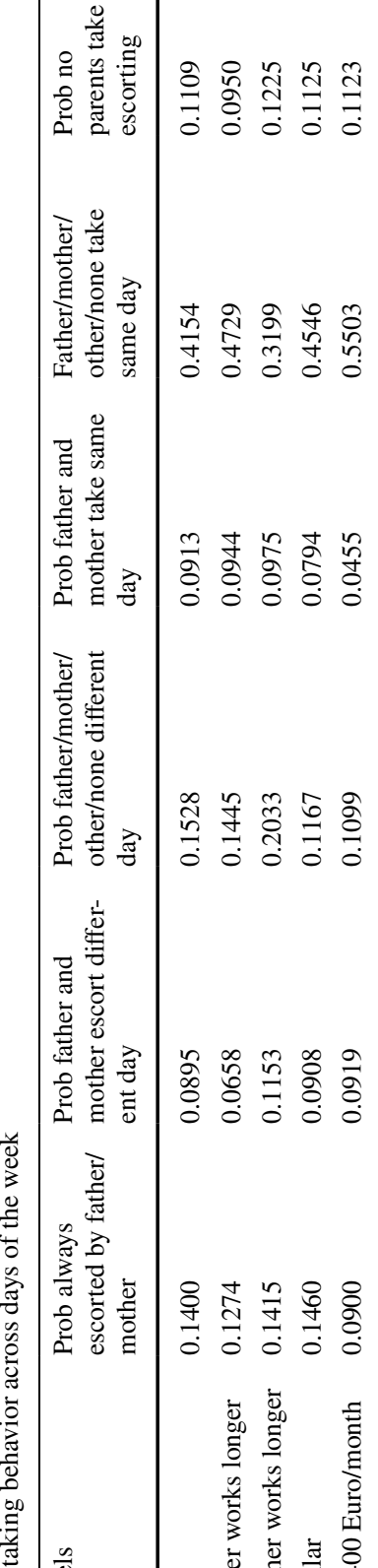

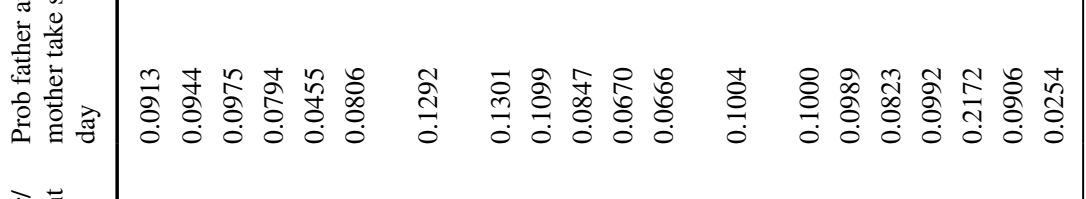

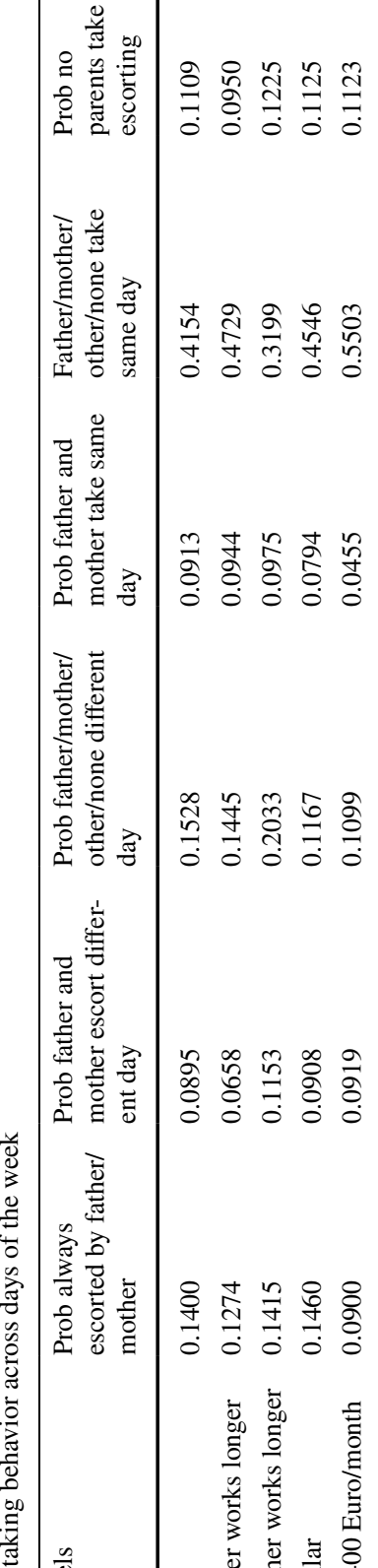

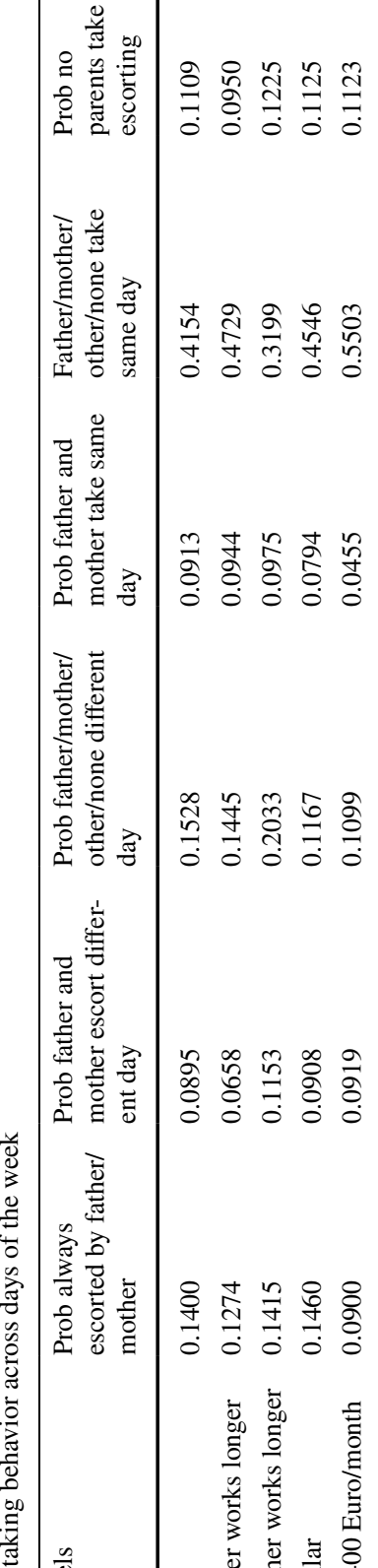

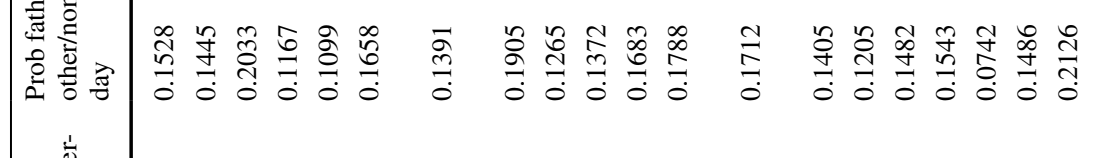

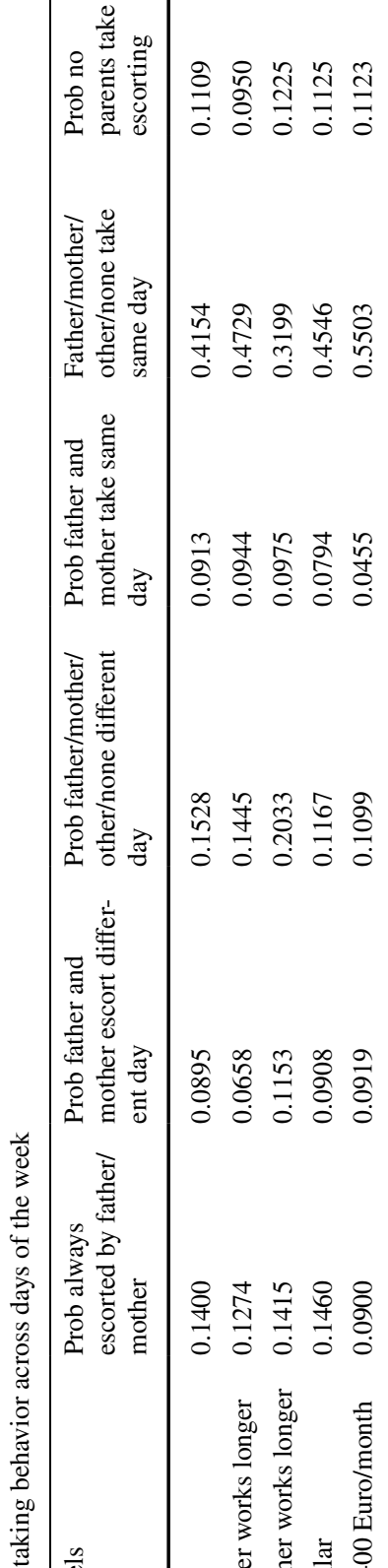

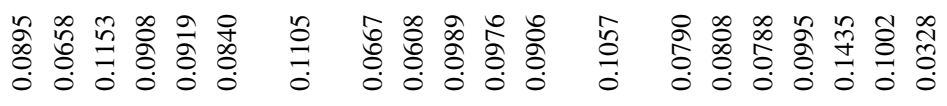

$$
\begin{aligned}
& \text { : }
\end{aligned}
$$

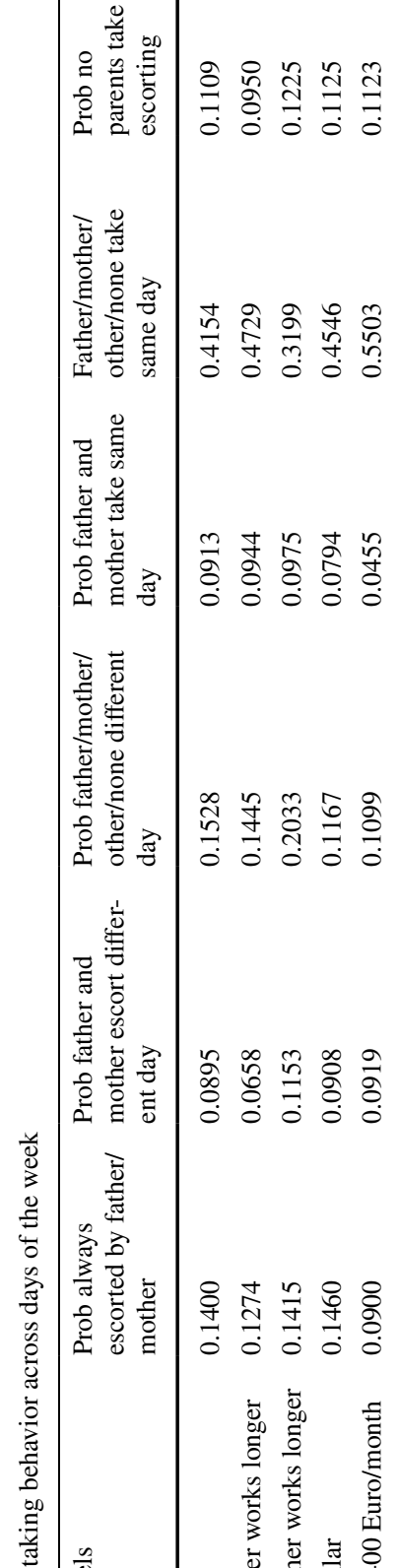

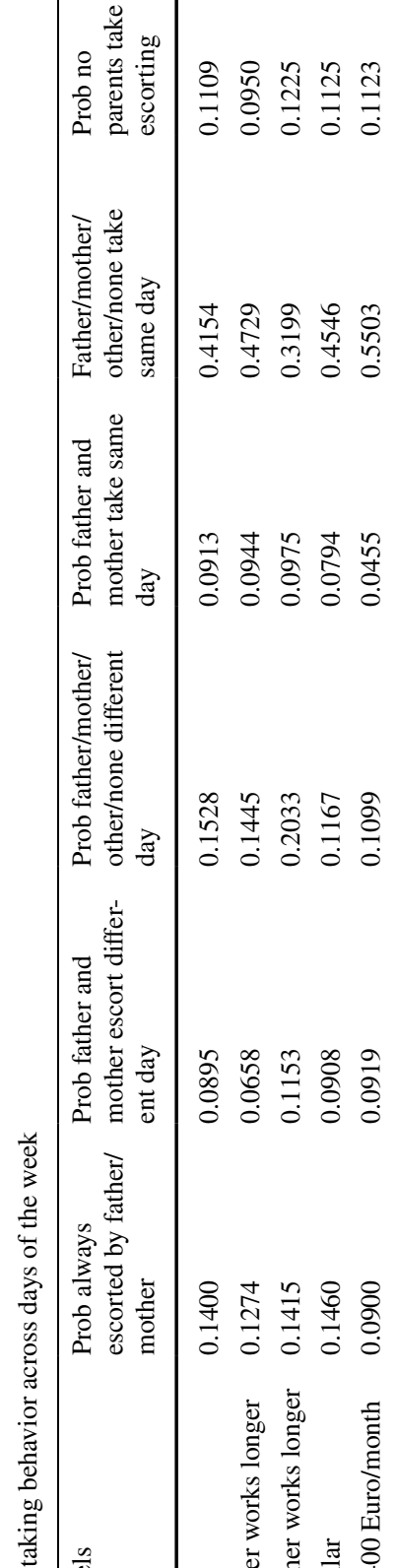

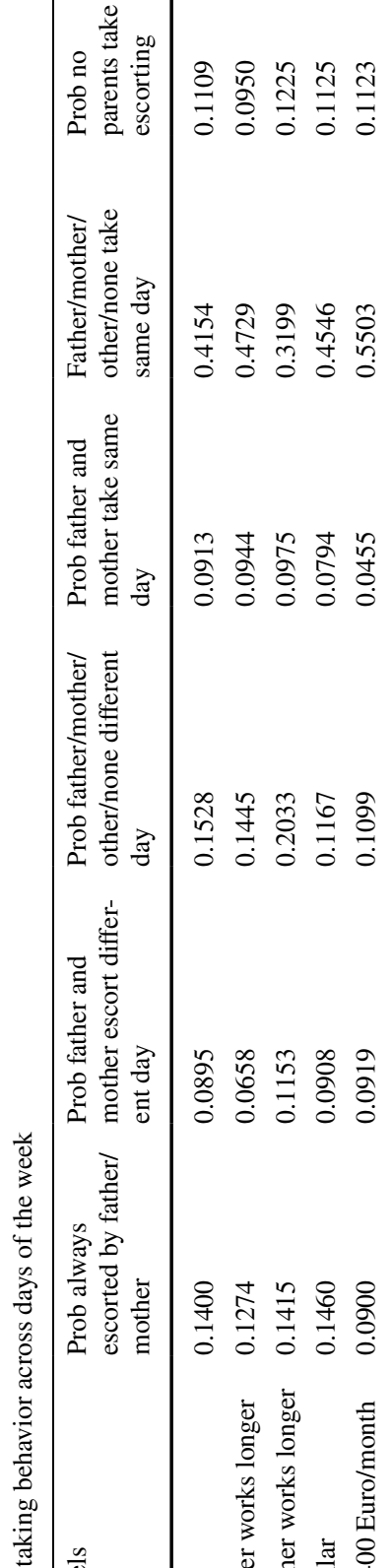

$$
\begin{aligned}
& \text { 旁旁 } \\
& \text { 旁旁 } \\
& \text { II }
\end{aligned}
$$

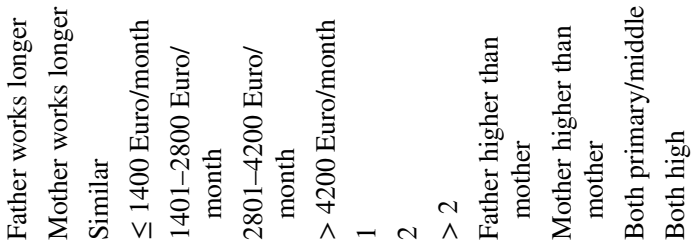

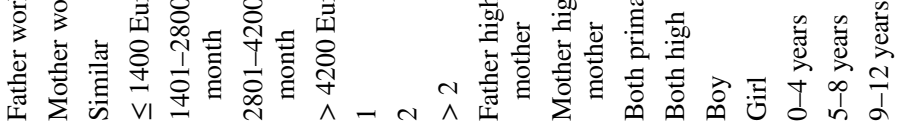

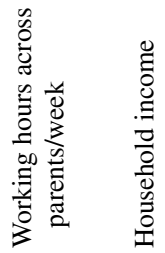

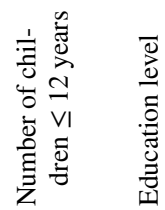

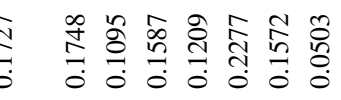
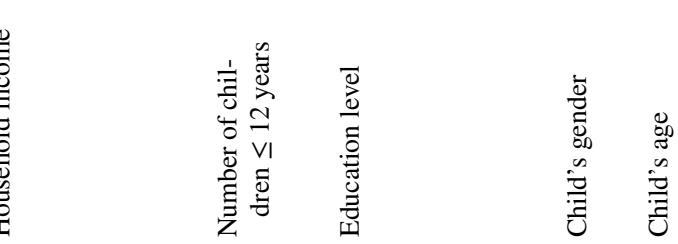

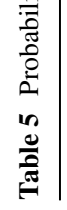


spending money on unemployment benefits and lower income tax and VAT, governments and employers should consider providing more financial support and liberal policies. More flexible start times, more flexibility to work at home, better synchronization of school and job start times are all examples that may reduce the pressures. On the other hand, to create more relief for parents, and furthermore to reduce pollution and protect the environment, both governments and schools can stimulate initiatives to encourage group/joint escorting. An example is that a primary school can provide service to help parents with a similar escorting route to share escorting. Similarly, local government can stimulate and sponsor small scale initiatives of group/joint escorting, which may be similar to car-sharing benefits.

Although gender differences in escorting have been found across the world, it would be interesting using the same methodology to repeat this study in an international comparison. For example, in China grandparents have a specific role; in Japan older children accompany younger children; some other countries have a school bus system, distances to school differ dramatically, etc. Hence, using a standardized data collection process, modeling the household scheduling process and analyzing the nature and intensity of escorting under these varying conditions would be highly interesting.

Author's contribution This paper is part of the Ph.D. study of Bilin Han. Jinhee Kim and Harry Timmermans are respectively co-promoter and first promoter. The conceptualization and study design are based on joint discussions in the research team. Bilin Han took the lead in questionnaire design and administration, analysis and manuscript writing. The other authors contributed in refining the analysis and editing and writing parts of the paper.

Open Access This article is distributed under the terms of the Creative Commons Attribution 4.0 International License (http://creativecommons.org/licenses/by/4.0/), which permits unrestricted use, distribution, and reproduction in any medium, provided you give appropriate credit to the original author(s) and the source, provide a link to the Creative Commons license, and indicate if changes were made.

\section{References}

Barker, J.: 'Manic Mums' and 'Distant Dads'? Gendered geographies of care and the journey to school. Health Place 17, 413-421 (2011)

Bernardo, Ch., Paleti, R., Hoklas, M., Bhat, Ch.: An empirical investigation into the time-use and activity patterns of dual-earner couples with and without young children. Transp. Res. Part A 76, 71-91 (2015)

Bradley, M., Vovsha, P.: A model for joint choice of daily activity pattern types of household members. Transportation 32, 545-571 (2005)

Colley, M., Buliung, R.N.: Gendered transport for the commute to school and work: a review of the literature. In: Proceedings Annual TRB Meeting. Washington DC, USA (2017)

Deka, D.: An explanation of the relationship between adults' work trip mode and children's school trip mode through the Heckman approach. J. Transp. Geogr. 31, 54-63 (2013)

Deka, D.: Impacts of standardizing school start time on children and household workers-an examination with NHTS data. J. Transp. Geogr. 59, 40-48 (2017)

Ehteshamrad, S., Saffarzadeh, M., Mamdoohi, A.: Role of children in parents' transit use behavior-an Iranian sample. J. Multidiscip. Eng. Sci. Technol. 4, 6442-6447 (2017a)

Ehteshamrad, S., Saffarzadeh, M., Mamdoohi, A.: Role of children in parents' car use behavior. Am. Sci. Res. J. Eng. Technol. Sci. 27, 179-188 (2017b)

Ekert-Jaffé, O.: Are the real time costs of children equally shared by mothers and fathers? Soc. Indic. Res. 101, 243-247 (2011)

Elias, W., Katoshevski-Cavari, R.: The role of socio-economic and environmental characteristics in schoolcommuting behavior: a comparative study of Jewish and Arab children in Israel. Transp. Policy 32, 79-87 (2014) 
Ermagun, A., Levinson, D.: Intra-household bargaining for school trip accompaniment of children: a group decision approach. Transp. Res. Part A 94, 222-234 (2016)

Ettema, D., Van der Lippe, T.: Weekly rhythms in task and time allocation of households. Transportation 36, 113-129 (2009)

Feng, Z., Boyle, P.: Do long journeys to work have adverse effects on mental health? Environ. Behav. 46, 609-625 (2014)

Fox, J., Patruni, B., Van Vuren, T., Adeeb, M.: Modelling escort travel in the West Midlands Region of the UK. In: Proceedings Annual Transportation Research Board Meeting, Washington, DC (2015)

Fyhri, A., Hjorthol, R.: Children's independent mobility to school, friends and leisure activities. J. Transp. Geogr. 17, 377-384 (2009)

Fyhri, A., Hjorthol, R., Mackett, R.L., Fotel, T.N., Kyttä, M.: Children's active travel and independent mobility in four countries: development, social contributing trends and measures. Transp. Policy 18, 703-710 (2011)

Giles-Corti, B., Wood, G., Pikora, T., Learnihan, V., Bulsara, M., Van Niel, K., Timperio, A., McCormack, G., Villanueva, K.: School site and potential to walk to school: the impact of street connectivity and traffic exposure in school neighborhoods. Health Place 17, 545-550 (2011)

Gliebe, J.P., Koppelman, F.S.: Modeling household activity-travel interactions as parallel constrained choices. Transportation 32, 449-471 (2005)

Gupta, S., Vovsha, P., Livshites, V., Maneva, P., Jeon, K.: Incorporation of escorting children to school in modeling individual daily activity patterns of household members. Transp. Res. Rec. 2429, 20-29 (2014)

He, S.Y.: Will you escort your child to school? The effect of spatial and temporal constraints of parental employment. Appl. Geogr. 42, 116-123 (2013)

He, S.Y., Giuliano, G.: Factors affecting children's journeys to school: a joint escort-mode choice model. Transportation 44, 199-224 (2017)

Hjorthol, R., Vagane, L.: Allocation of tasks, arrangement of working hours and commuting in different Norwegian households. J. Transp. Geogr. 35, 75-83 (2014)

Ho, C., Mulley, C.: Intra-household interactions in transport research: a review. Transp. Rev. 35, 33-55 (2015)

Hsu, H.P., Saphores, J.D.: Impacts of parental gender and attitudes on children's school travel mode and parental chauffeuring behavior: results for California based on the 2009 National Household Travel Survey. Transportation 41, 543-565 (2014)

Kyttä, M., Hirvonen, J., Rudner, J., Pirjola, I., Laatikainen, T.: The last free-range children? Children's independent mobility in Finland in the 1990s and 2010s. J. Transp. Geogr. 47, 1-12 (2015)

Lam, W.W., Loo, B.P.: Determinants of children's independent mobility in Hong Kong. Asian Transp. Stud. 3, 250-268 (2014)

Liao, F., Rasouli, S., Timmermans, H.J.P.: Incorporating activity-travel time uncertainty and stochastic space-time prisms in multi-state supernetworks for activity-travel scheduling. Int. J. Geogr. Inf. Sci. 28, 928-945 (2014)

Lin, J.-J., Chang, H.-T.: Built environment effects on children's school travel in Taipei: independence and travel mode. Urban Stud. 47, 867-889 (2010)

Lopes, F., Cordovil, R., Neto, C.: Children's independent mobility in Portugal: effects of urbanization degree and motorized modes of travel. J. Transp. Geogr. 41, 210-219 (2014)

McDonald, N.C., Aalborg, A.E.: Why parents drive children to school: implications for safe routes to school programs. J. Am. Plann. Assoc. 75, 331-342 (2009)

Mehdizadeh, M., Nordfjaern, T., Mamdoohi, A.: The role of socio-economic, built environment and psychological factors in parental mode choice for their children in an Iranian setting. Transportation (2016). https://doi.org/10.1007/s11116-016-9737-z

Mitra, R., Buliung, R.N.: The influence of neighborhood environment and household travel interactions on school travel behavior: an exploration using geographically-weighted models. J. Transp. Geogr. 36, 69-78 (2014)

Motte-Baumvol, B., Bonin, O., Belton-Chevallier, L.: Who escort children: mum or dad? Exploring gender differences in escorting mobility among Parisian dual-earner couples. Transportation 44, 1-19 (2017)

Offer, S.: Time with children and employed parents' emotional well-being. Soc. Sci. Res. 47, 192-203 (2014)

Pojani, D., Boussauw, K.: Keep the children walking: active school travel in Tirana, Albania. J. Transp. Geogr. 38, 55-65 (2014)

Rasouli, S., Timmermans, H.J.P.: New impetus to theoretical and empirical perspectives on space-time behavior: stochastic representation, dynamic choice sets and activity spaces. Environ. Plann. B 41, 954-959 (2014a) 
Rasouli, S., Timmermans, H.J.P.: Uncertain travel times and activity schedules under conditions of spacetime constraints and invariant choice heuristics. Environ. Plann. B 41, 1022-1030 (2014b)

Rasouli, S., Timmermans, H.J.P.: Effects of travel time delay on multi-faceted activity scheduling under space-time constraints: a simulation study. Travel Behav. Soc. 1, 31-35 (2014c)

Rasouli, S., Timmermans, H.J.P.: Applications of theories and models of choice and decision-making under conditions of uncertainty in travel behaviour research. Travel Behav. Soc. 1, 79-90 (2014d)

Scheiner, J., Holz-Rau, C.: Gendered travel mode choice: a focus on car deficient households. J. Transp. Geogr. 24, 250-261 (2012)

Scheiner, J.: School trips in Germany: gendered escorting practices. Transp. Res. Part A 94, 76-92 (2016)

Scheiner, J., Holz-Rau, C.: Women's complex daily lives: a gendered look at trip chaining and activity pattern entropy in Germany. Transportation 44, 117-138 (2017)

Schwanen, T., Ettema, D.: Coping with unreliable transportation when collecting children: examining parents' behavior with cumulative prospect theory. Transp. Res. Part A 43, 511-525 (2009)

Srinivasan, S., Bhat, C.R.: A multiple discrete-continuous model for independent- and joint-discretionary activity participation decisions. Transportation 33, 497-515 (2006)

Tetali, S., Edwards, P., Murthy, G.V.S., Roberts, I.: How do children travel to school in urban India? A cross-sectional study of 5,842 children in Hyderabad. BMC Public Health 16, 1-7 (2016)

Timmermans, H.J.P., Borgers, A.W.J., van Dijk, J., Oppewal, H.: Residential choice behaviour of dual earner house-holds: a decompositional joint choice model. Environ. Plann. A 24, 517-533 (1992)

Vovsha, P., Petersen, E.: Escorting children to school: statistical analysis and applied modeling approach. Transp. Res. Rec. 1921, 131-140 (2005)

Yarlagadda, A.K., Srinivasan, S.: Modeling children's school travel mode and parental escort decisions. Transportation 35, 201-218 (2008)

Zhang, J., Timmermans, H.J.P., Borgers, A.: Utility-maximizing model of household time use for independent, shared, and allocated activities incorporating group decision mechanisms. Transp. Res. Rec. 1807, 1-8 (2002)

Zhang, J., Timmermans, H.J.P., Borgers, A.W.J.: A model of household task allocation and time use. Transp. Res. Part B 39, 81-95 (2005)

Bilin Han is a PhD candidate in Urban Planning of Building Environment department at the TU/e. Her supervisor is Professor Harry Timmermans. Her PhD project is focused on work schedule arrangement in dual-earner households with children.

Jinhee Kim is Assistant Professor of the Urban Planning Group at the TU/e. He received a PhD in the Urban Planning and Engineering emphasizing on transportation planning from Yonsei University, Korea. $\mathrm{He}$ has research interests in modeling behavioral process in activity-travel decisions and developing advanced discrete choice models. The models aim to better understand and forecast behavioral adoption and adaptation of urban and transportation projects.

Harry Timmermans is Professor of Urban Planning at the TU/e. Research activities of his multidisciplinary group concern the development and application of innovative models and ICT tools for urban planning and transportation. He has been awarded prestigious grants, and won many (best paper) awards with his $\mathrm{PhD}$ students. He serves on TRB and WCTR Committees. He has co-authored more than 600 publications in urban planning, transportation, artificial intelligence, marketing, and environmental psychology. 